\title{
Corpo: a primeira mídia. Aspectos contemporâneos e multidisciplinares
}

\author{
Maristela ROCHA
}

*Mestre em Comunicação e Cultura pela UFRJ. Graduada em Comunicação Social, Jornalismo, pela UFJF. Professora da Universidade Vale do Rio Verde, Três Corações, nos cursos de Administração/FGV, Núcleo de Humanidades (Psicologia, Medicina Veterinária, Odontologia, Direito, Educação Física, Engenharia Ambiental, Ciências Contábeis, Agronomia, Farmácia).maristelarochafgv3cor@gmail.com; maristelarocha@yahoo.com

Recebido em: 30/10/2012 - Aprovado em: 21/12/2012 - Disponibilizado em: 30/12/2012

\begin{abstract}
RESUMO:
A história universal deixa evidente que o corpo humano sempre foi objeto de estudo, contemplação, análise, desejo. Pretendemos analisar e ressaltar a importância do corpo como uma primeira mídia, como forma de interação social. Body building, body modification, body art, cinésica são conceitos relevantes e presentes nesse trabalho por demonstrarem a capacidade simbólica do corpo e o seu uso como meio de comunicação, como uma imensa rede de interfaces. Transformar, adornar, alterar, mutilar o corpo são fatos comuns em várias culturas em todo o mundo. $\mathrm{O}$ corpo na comunicação midiática de massa também é evidenciado, assim como a relação entre corpo e risco devido ao uso das mais diversas substâncias capazes de alterar a performance do ser humano. Há muitos sentidos em uma linguagem sem palavras e a comunicação de conduta, que leva em consideração aspectos socioculturais, mostra o quanto o estudo do corpo propicia entendimento das relações de natureza biopsicossocial. Esperamos contribuir para análises contemporâneas, inter e multidisciplinares sobre a comunicabilidade corporal, que transmite informações reveladoras através de pistas simbólicas que demonstram exterior e interioridade do indivíduo.
\end{abstract}

PALAVRAS-CHAVE: Body building. Body modification. Body art. Cinésica. Mídia.

\begin{abstract}
:
Universal history makes it clear that the human body has always been a subject of study, contemplation, analysis and desire. We intend to analyze and highlight the importance of the body as a first medium, as a way of social interaction. Body building, body modification, body art and kinesics are relevant concepts and present in this work, as they show the symbolic capacity of the body and its use as a mean of communication, with a wide web of interfaces. Transforming, adorning, altering, mutilating the body are common facts in various cultures all over the world. The body in media mass communication is also evidenced, as well as the relation between body and given the use of the most varied substances able to alter the human performance. There are a lot of senses in language without words and conduct communication, which takes into account sociocultural aspects, showing how the study of the body fosters understanding of the relations of biopsychossocial nature. We hope to contribute to contemporary, inter and multidisciplinary analysis about corporal communicability, which transmits revealing information by symbolic clues that displays exteriority and interiority of an individual.
\end{abstract}

KEYWORDS: Body building. Body modification. Body art. Kinesics. Media.

\section{Introdução}

A sociedade, em todos os tempos, cria estereótipos da imagem corporal, moldando a estética de acordo com os padrões de beleza vigentes. Essa mesma sociedade rejeita corpos mutilados ou distantes dos valores em voga. As pessoas procuram uma maneira de identificação com o outro, encaixando-se no padrão estabelecido e essa corrida pela 
adaptabilidade é, muitas vezes, uma fonte de desajuste emocional e físico.

$\mathrm{O}$ século XX nos legou um complexo de situações que nos desestabilizam a cada momento, enfatizadas por características como a globalização, a alta tecnologia, o consumismo e o hedonismo, o niilismo, o pastiche, o simulacro. Isso porque o indivíduo na contemporaneidade é essencialmente performático e quando essa performance é abalada, as inúmeras facetas corporais são afetadas. O século XXI também é marcado pelo limite diário entre a vida e a morte; às vezes, pela morte em plena vida.

Corpo espetáculo, corpo do prazer, do risco, dos extremos entre a obesidade e a anorexia, body building ${ }^{i}$ e body modification ${ }^{i i}$, body art $^{i i i}$ apresentam-se como marcantes características contemporâneas. As ciências biomédicas, cada vez mais, vêm acompanhando essa tendência e o aparato tecnológico permite que possamos regrar as formas de nosso corpo, reduzindo a distância entre o que deseja a mente e o seu reflexo no corpo, através de moderadores de apetite, substâncias que permitam maior desempenho sexual, drogas para insônia, depressão ou para melhorar o desempenho físico, para adiar o envelhecimento. Isso porque o corpo evidencia comunicabilidade, performance, movimento.

Os videoclipes, as publicidades, as bancas de revistas destituem de sentido não apenas todas as aparências que não se enquadram nos seus moldes, mas, mais do que isso, todos aqueles que ficam na sombra, à margem das luzes gloriosas do exibicionismo. Na luta por alcançar pelo menos uma réstea de luz, a corrida rumo à juventude e à perfeição teleguiadas "é hoje uma maratona que alcança jovens e idosos de diversas classes sociais, mas estes não conseguem ver o pódio, porque se trata de uma corrida infinita" (SANT'ANNA apud SANTAELLA, 2004, p. 131).

As novas tecnologias de comunicação vêm estabelecer a possibilidade de mudança na experiência de nossos corpos, abrindo novas possibilidades físicas, sensoriais, emocionais. Corpo que move, corpo que dança. A mão que rege, a voz que encanta, os pés que marcam o ritmo dinamizando a música, a vida. Emoções que a tecnologia não consegue apagar e que nos levam a concluir que o corpo é a primeira mídia da história da humanidade: é o meio de expressão, de comunicação, que revela as várias fases da trajetória do homem na Terra.

\section{A voz do corpo}

O ser humano, além de utilizar os recursos verbais e vocais, também faz uso simultâneo de recursos não-verbais, que transmitem importantes mensagens por meio dos gestos, das expressões faciais, da postura, da aparência física e até da roupa e dos adereços. Conforme explica Cláudia Simone Godoy Cotes, somente há poucos anos a Fonoaudiologia começou a atentar cientificamente para o comportamento comunicativo do corpo humano.

...muito estudada anteriormente por ciências afins, como a Lingüística, que 
interpreta os gestos como um enunciado; a Psicologia, que estuda as unidades do comportamento corporal para o entendimento psicológico do indivíduo; a Psiquiatria, que relaciona os movimentos do corpo ao caráter, emoções e reações do ser humano; a Sociologia, que relaciona os gestos da pessoa ocorrendo dentro de um contexto sócio-econômico; a Antropologia, que estuda a influência cultural sobre as mudanças corporais; e a Cinésica, que estuda minuciosamente o comportamento não-verbal. (COTES) ${ }^{\text {iv }}$

Os sinais de comunicação reforçam, substituem ou contrariam a fala, o saber, os gestos, a expressão facial (movimento de sobrancelhas, olhares, sorrisos); a postura (movimentos e inclinações do corpo); a ocupação do espaço (proximidade, distância e toque). Esses sinais, chamados de paralinguísticos, são próprios de cada cultura e por meio deles é realizada a comunicação humana não-verbal.

Birdwhistell, considerado o pioneiro nos estudos do movimento do corpo humano, a Cinésica, revela na obra Kinesics and context - essays on body - motion communication que o interesse pela linguagem gestual cresceu muito depois da I e II Guerra Mundial, pois os soldados falavam línguas diferentes e um simples gesto universal, como um aperto de mão, por exemplo, poderia ter várias interpretações, da bravura à covardia. $\mathrm{O}$ autor partiu da premissa de que as emoções humanas básicas, como a alegria e o medo, também se manifestam do mesmo modo, em várias culturas (BIRDWHISTEL, 1970, p.21).
Birdwhistell ressalta ainda que os gestos ocorrem devido ao fato de haver informações armazenadas no inconsciente que são facilmente lembradas, por estarem relacionadas a um comando cerebral central que reconhece os gestos imediatamente. São as manifestações afetivas, conforme explica Maria Júlia Paes da Silva (SILVA, 2006, p.63).

A autora Maria Júlia relata ainda que Ekman e Friesen, representativos investigadores no campo da gestualidade, apresentaram fotografias de norte-americanos com expressões faciais de felicidade, tristeza, medo, raiva, surpresa e nojo a pessoas de cinco países (Japão, Brasil, Estados Unidos, Chile e Argentina), solicitando a elas que respondessem de acordo com o que viam. O índice de acerto/concordância em todos os países foi bastante alto, atingindo uma média de $85 \%$. Repetindo o experimento com pessoas de uma comunidade não-alfabetizada na Nova Guiné, sem influência da cultura norte-americana, obtiveram resultados semelhantes, evidenciando que essas expressões faciais de emoção são universais, ou seja, possuem significados em várias culturas (SILVA, 2006, p. 63).

Quanto à fala, utilizamos recursos vocais diferentes para transmitir uma informação como variação de frequência, que determinam curvas entonacionais diferentes, intensidade, velocidade e duração. A dicção também ocupa um lugar necessário em todo o 
discurso. Foram os poetas que primeiro aprenderam a trabalhar diferentes ações da voz: ora forte, fraca ou média, assumindo os diferentes tons alternadamente, empregando ritmo. A entonação consiste em variações de altura (pitch) na palavra, e podem ser determinadas pela emoção ou pela intenção da veiculação da mensagem.

Segundo a fonoaudióloga Eudosia Acuña Quinteiro, “o corpo é o grande registro histórico de um ser, pode revelar indícios ou pistas que, se bem compreendidos pelo terapeuta, estabelecem o melhor caminho para uma terapia bem sucedida" (QUINTEIRO, 2000, p. 2).

Estudos da Psicologia Social revelam que a expressão do pensamento se faz $7 \%$ com palavras, $38 \%$ com sinais paralinguísticos e $55 \%$ por meio de sinais do corpo.

Birdwhistell considera que somente $35 \%$ do significado social de qualquer interação corresponde às palavras pronunciadas, pois o homem é um ser multissensorial que, de vez em quando, verbaliza (SILVA, 2006, p. 46).

Justamente por ser uma mídia, o corpo humano demanda estudos multidisciplinares. Anteriormente, havia a busca pelo entendimento segundo aspectos biopsicológicos; posteriormente, ganharam ênfase também os estudos do corpo inserido na sociedade, na cultura, revelando a cinésica e a comunicação de condutav ${ }^{v}$. Na atualidade, as relações tecnológicas levam a novas pesquisas e profundas reflexões. As certezas foram problematizadas. O corpo continua sendo foco de múltiplas investigações e assim deverá ser, independente de tempo e espaço.

\section{Corpo em rádio e TV}

Quando falamos em mídia, logo associamos a palavra aos meios de comunicação tradicionais: rádio, televisão, internet, periódico, hipermídia. Torna-se oportuna uma reflexão sobre o corpo humano e as mídias tradicionais; nesse trabalho, escolhemos a radiofônica e a televisiva. A comunicação midiática é uma manifestação incontestável de poder, já que é uma das formas mais prestigiosas e rápidas de influenciar o comportamento alheio; nesse sentido, é impossível não passar pela esfera dos mass media.

É algo realmente sedutor pensar nessa relação entre o corpo (que defendemos como a primeira mídia) e os veículos de massa. O corpo torna-se instrumento, complemento, extensão do rádio e da TV. Rememorando McLuhan, a forma de um meio social está diretamente relacionada às novas maneiras de percepção instauradas pelas tecnologias da informação (McLUHAN, 1980).

Como essa análise demanda pesquisa multidisciplinar, a Fonoaudiologia ${ }^{\mathrm{vi}}$ também nos favorece como referencial teórico. Atualmente, os fonoaudiólogos vêm demonstrando grande interesse pelos estudos de estética vocal, devido ao aumento de assessorias e atendimentos prestados junto aos 
profissionais que lidam com a voz e com o corpo para alcançarem maior expressividade em seu trabalho.

No caso da mídia televisiva, sabemos que o emissor precisa ser incisivo, mostrar crédito na mensagem veiculada, fixando o olhar na câmera - não podemos, obviamente, subestimar o poder do olhar, da expressão facial. A TV trabalha com enquadramentos fechados, o que mostra todos os detalhes e amplia os gestos, por isso é preciso cuidado para não exagerar na gesticulação. Saber gesticular também é fundamental para transmitir bem a informação. A performance é, consequentemente, elemento importante na veiculação da notícia.

Em televisão, gesticular as mãos pode ser um ato comprometedor porque estas revelam o mundo interior de uma pessoa para o mundo exterior, o mesmo não acontece em rádio, já que os gestos podem servir para enfatizar a mensagem que não vai ser vista, apenas ouvida. A mão humana é, realmente, tão importante, que os filósofos da Antiguidade já a designavam como a segunda inteligência.

Encontramos explicação sobre esse aspecto em Bueno, na obra Manual de califasia, calirritmia e arte de dizer. Segundo ele, as mãos podem ficar em seis posições: para dentro, significando repouso, piedade; para a frente, indicando referência à pessoa que está falando; para baixo, exprimindo respeito, autoridade; para o alto, dando a ideia de prece; para a frente, indicando defesa, recusa e para os lados, exprimindo um gesto violento, separação (BUENO, 1964, p. 22).

Quanto aos dedos, devem estar ligeiramente abertos, com as extremidades um pouco encurvadas; nunca devem estar virados para dentro (dobrados). Já o dedo indicador, desempenha grande papel na gesticulação e merece atenção e cuidado (BUENO, 1964, p. 22).

A expressão facial na televisão é salientada pela aproximação das câmeras, por isso é fundamental que o apresentador de telejornal demonstre uma adequada mobilidade facial. Da mesma forma, a postura deve ser observada, já que a mudança da mesma indica o início e o término de unidades de comunicação e a maneira como os participantes se relacionam.

Além disso, há o aspecto da produção vocal: o dorso encurvado, peito afundado e o tronco dobrado na região do diafragma dificultam o controle respiratório; da mesma forma, o pescoço de pombo, o queixo levantado ou para frente desfavorecem a emissão vocal. A cabeça deve ficar na posição mais natural possível, sem nenhuma rigidez, mantendo a horizontalidade do olhar.

Segundo o apresentador Cid Moreira, "só pode ser locutor, bom profissional, quem souber mesmo enfrentar a câmera. Movimentos pequenos tornam-se grandes e significativos em televisão". vii $\mathrm{O}$ ideal é que o apresentador mantenha uma postura ereta, 
olhando diretamente na lente da câmera, mantendo as costas firmes e os dois pés apoiados no chão (e um pouco distantes).

A postura em relação à voz é, realmente, importante. Mudar de postura a cada mudança de assunto é um recurso nãoverbal muito importante para os profissionais que trabalham em telejornalismo; além de tudo, realçam a expressividade do comunicador. Quando os repórteres movimentam as mãos, os braços e o próprio corpo durante as notícias ou marcam com gestos a ênfase ao que está sendo dito, estão regulando, ou seja, regendo o seu corpo porque tais gestos dinamizam a comunicação denotam interatividade.

Corpomídia, corpo e mídia, corpo na mídia. "O corpo sai dele mesmo, com velocidade e espaço distintos", como explica Carlos Moreno em A virtualização do corpo. É cada vez mais difícil dizer que o corpo (coletivo) termina aqui ou lá: "a ilusão de separação é superada pela visibilidade da mistura. Isso possibilita a compreensão de que o 'corpo' não era só o que se tinha como imagem dele" (MORENO apud VILLAÇA, GÓES, KOSOVSKI, 1999, p. 50).

Em conformidade, Christine Greiner explica que o corpo não é apenas um meio por onde a informação simplesmente passa, "o corpo é o resultado desses cruzamentos, e não um lugar onde as informações são apenas abrigadas" (GREINER, 2005, p. 131). Para as pessoas que utilizam o corpo - em especial a voz - profissionalmente, fica o convite para uma imersão nesse estudo que, certamente, é uma obra aberta.

\section{Corpo, arte, vida e morte}

Multissensorial, humano, remodelado, protético, digitalizado: cibernético. É o corpo no Pós-Modernismo. O corpo humano como fruto de sua crescente ramificação em variados sistemas de "extensões tecnológicas até o limiar das perturbadoras previsões de sua simulação na vida artificial e de sua replicação resultando da decifração do genoma" é o que Lúcia Santaella chama de corpo cibernético (SANTAELLA, 2004, p.98).

Se fôssemos fazer um relato sobre a história do corpo e seus mais diversos significados, manifestações, representações, simbolismos, teríamos que retratar a própria história da humanidade. São muitos os autores que tratam do assunto. A arte oratória, por exemplo, fundamentada em princípios disciplinados de conduta, teve origem na Sicilia, no século V a.C.

Em Atenas, os sofistas desenvolviam o aprendizado na arte de falar praticando leitura em público e estabelecendo debates. Os romanos sofreram influência cultural dos gregos e legou-nos Cícero (106 a.C.- 46.a. C.), considerado o maior orador romano. E como não mencionar o Homem Vitruviano, de Leonardo da Vinci (1452-1519) $?^{\text {viii }}$ 
Em outros tempos e espaços, Marx (1818-1883), Nietzsche (1844-1900) e Freud (1856-1939) nos legaram importantes contribuições sobre o estudo do corpo e sua relação com o mundo, evidenciando aspectos que extrapolam a suposta dimensão exclusivamente natural do corpo, até então mantida sob a tutela da fisiologia e da anatomia.

Lúcia Santaella ressalta que, a partir da obra de Foucault (1926-1984), os estudos propiciam "uma nova zona de visibilidade do corpo"; acentuam-se as análises que procuram pensar a maneira como o corpo - doença, sexualidade, prazeres, gestos, posturas, sensorialidade - é atravessado por instituições, instrumentos, poderes (BRUNO apud SANTAELLA, 2004, p. 27).

E essa nova visibilidade do corpo à qual Lúcia Santaella se refere vem merecendo atenção por parte de pesquisadores de várias áreas do conhecimento. A discussão em torno da arte, cultura e tecnologia, por exemplo, parece encontrar hoje no corpo e suas imagens um núcleo para debater o tempo e o espaço contemporâneos.

Em corpo e risco, Paulo Vaz explica como as novas tecnologias de comunicação transformaram a experiência do corpo, assim como as tecnologias biomédicas:

As tecnologias biomédicas pesquisam e propõem aos indivíduos que já mecanismos tecnológicos para se regrar a forma do corpo - moderadores de apetite, óleos sem colesterol ou caloria, drogas para controlar a impotência sexual, a insônia, a angústia, a depressão, etc. - e estender, para o indivíduo, a duração do pensamento na matéria (VAZ apud VILLAÇA, GÓES, KOSOVSKI, 1999, 161).

São os avanços da biologia, da engenharia genética, da medicina, as máquinas exploratórias para o diagnóstico médico, a multiplicação crescente das imagens do corpo nas mídias, as simbioses cada vez mais íntimas do corpo com as tecnologias que permitem a visualização, bem como análise do interior do corpo (SANTAELLA, 2004, p.79).

Terezinha Petrúcia da Nóbrega ressalta que, nesse debate sobre a consciência do corpo, é preciso considerar também o convívio com a biotecnologia, os meios digitais que interferem na função somática, entre outras formas de interação do humano com a máquina. É criado um hipercorpo, que diz respeito ao processo de virtualização, considerando-se os meios de comunicação e a biotecnologia, como transplantes e cirurgias (NÓBREGA, 2005, p.52).

A autora remete ao filósofo Pierre Lévy "Meu corpo pessoal é a atualização temporária de um enorme corpo híbrido, social e tecnobiológico" (LÉVY apud NÓBREGA, 2005, p. 98). Dessa forma, pelo corpo, pela expressão corporal, diferenciamonos das outras pessoas, marcamos nossa presença, nossa identidade. O lógico igualanos, o sensível diferencia-nos (NÓBREGA, 2005, p.52). 
Banalização da vida, da saúde, da morte. O Brasil é o segundo país no mundo que mais se realiza cirurgias plásticas, ficando atrás dos Estados Unidos. De acordo com a Sociedade Brasileira de Cirurgia Plástica ${ }^{\text {ix }}$, o número de procedimentos anuais chega a 629 mil. Em 2011, foram realizadas mais de 640 mil cirurgias plásticas no Brasil;

Ainda segundo a pesquisa, $82 \%$ das cirurgias foram realizadas em mulheres. Elas preferem corrigir as imperfeições do pescoço para baixo: principalmente nas mamas. Em segundo lugar, a lipoaspiração combinada com outras operações. Já os homens se preocupam mais com o rosto: pálpebras e nariz.

Ainda de acordo com o levantamento, no Brasil há um médico cirurgião plástico para cada 44.000 habitantes - número considerado elevado pelos especialistas. Os Estados Unidos, por exemplo, possuem um profissional para cada 50.000 pessoas.

Aumenta o acesso às tecnologias que modificam o corpo, mas há aumento também do número de procedimentos mal-sucedidos e dos óbitos. Vários casos vêm sendo divulgados na mídia, como o da atriz Pamela Baris do Nascimento, 27 anos, que faleceu durante uma lipoaspiração no Hospital Green Hill no Ipiranga, Zona Sul de São Paulo, em 19 de outubro de 2012. ${ }^{x}$

O corpo natural vai tornado-se, cada vez mais, artificial, manipulado, modificado, construído. Segundo Marina Guzzo, em
Riscos da beleza e desejos de um corpo $\operatorname{arquitetado}^{x i}$, falar de risco de alterações do corpo por meio de substâncias ou práticas especializadas é contar a história do corpo.

\begin{abstract}
É olhar para a história por meio dele e antes de tudo problematizar uma prática corporal, um fazer do corpo que envolve não só sentidos para quem escolhe, mas também para quem consome as várias substâncias oferecidas para essas práticas. Nesse caso especificamente o corpo serve de suporte e de metáfora para o risco. ${ }^{\text {xii }}$
\end{abstract}

Segundo o filósofo francês MerleauPonty, o corpo não é objeto, nem ideia, é expressão singular da existência do ser humano que se move. O corpo é sexualidade, é linguagem, é movimento, é obra de arte (PONTY apud NÓBREGA, 2005, p.30).

A body art ganha ênfase a partir do anos 1960. Além do francês Duchamp (Marcel Duchamp/ 1882-1968), podem ser considerados precursores Yves Klein (18281962), que usava corpos femininos como "pinceis vivos", o americano Vito Acconci (1940) e o italiano Piero Manzoni (19331963). A body art retoma as experiências pioneiras dos surrealistas e dadaístas de uso do corpo como matéria- prima, além de reeditar práticas das chamadas sociedades primitivas. $^{\text {xiii }}$

Entretanto, há práticas de body art que exemplificam nossa análise sobre corpo e risco. Em Rubbing Piece (1970), encenado em Nova Iorque, Vito Acconci esfrega o próprio braço até produzir uma ferida. "O 
sangue, o suor, o esperma, a saliva e outros fluidos corpóreos mobilizados nos trabalhos revelam o corpo como suporte."xiv

\section{Conclusão}

É sempre surpreendente atualizar a pesquisa sobre o corpo como mídia. Tamanha riqueza não nos permite estudá-lo com base em apenas uma área do conhecimento. Dos conceitos elementares de comunicação ao estudo da cinésica e da comunicação de conduta; do corpo biológico ao cibernético; do corpo na arte ao corpo como suporte para a arte. Há múltiplas teorias de inúmeros pesquisadores. Parafraseando o título da obra de Christine Greiner, o corpo revela pistas para estudos inter e multidisciplinares.

Pensar na cultura imagética que retrata o corpo ao longo da história e ver a dimensão contemporânea propiciada pela body art, assim como a tecnologia a serviço da construção corporal, nos dá o exato entendimento do quanto esse estudo é relevante por um tempo também indeterminado na história da humanidade.

Não menos instigante é pensar no corpo na mídia radiofônica e televisiva. De acordo com o gênero e a emissora, muitas modificações vão aparecendo em função da performance corporal. $\mathrm{O}$ estilo de cada âncora varia de acordo com a linha editorial do programa que apresenta. Percebemos hoje um modelo flexível, que permite mais informalidade e descontração não apenas na linguagem, como também na dinâmica dentro do estúdio.

No que se refere ao corpo e ao risco, é notória a banalização da vida e da morte em prol de padrões de beleza socialmente definidos. O aumento da tecnologia é acompanhado do crescimento do número de óbitos. Todas as considerações nos levam a crer que o corpo é e a primeira mídia e que, através de tempos e espaços diferenciados, estará sempre registrando a história do homem na terra.

\section{REFERÊNCIAS BIBLIOGRÁFICAS:}

* DAVIS, Flora. In: SILVA, Maria Júlia Paes. Comunicação tem remédio. A comunicação nas relações interpessoais em saúde. São Paulo: Loyola, 2006. p. 45.

BARBEIRO, Heródoto e LIMA, Paulo Rodolfo de. Manual de Radiojornalismo. Rio de Janeiro: Elsevier, 2003.

BEUTTENMÜLLER, Glorinha e LAPORT, Nelly. Expressão vocal e expressão corporal. Rio de Janeiro: Enelivros, 1992.

BIRDWHISTELL. Kinesis and context essays on body - motion communication. Pennsylvania: Peguin Books, 1970.

BOONE, Daniel R. e PLANTE, Elena. Comunicação humana e seus distúrbios. Trad. Sandra Costa. Porto Alegre: Artes Médicas, 1994.

BUENO, Francisco. Manual de califasia, calirritmia e arte de dizer. São Paulo: Saraiva, 1964. 
CARVALHO, Irene Mello. Introdução à Psicologia nas Relações Humanas. Rio de Janeiro: FGV, 1970.

CHERRY, Colin. A comunicação humana. São Paulo: Cultrix, 1980.

COTES, Claudia Simone Godoy. Apresentadores de Telejornal: Análise descritiva dos recursos não-verbais e vocais durante o relato da notícia. Disponível em: http://www.claudiacotes.com.br/site/downloa d/tese_mestrado.pdf Acesso em 01.10.2012.

FONOAUDIOLOGIA.com. Disponível em http://www.fonoaudiologia.com/. Acesso em 01.10.2012.

GAYOTTO, Lucia Helena. Voz do ator: a partitura da ação. São Paulo: Summus, 1997.

GREINER, Christine. O corpo. Pistas para estudos indisciplinares. São Paulo:

Annablume, 2005.

GONÇALVES, M. H. B. Comunicação verbal e não-verbal. Rio de Janeiro: SENAC, 1996.

GUZZO, Marina. Riscos da beleza e desejos de um corpo arquitetado. Disponível em www.rbceonline.org.br/revista/index.php/RB CE/article/view/139 . Acesso em 01.10.2012.

MEDIPLAN. Brasil tem mais cirurgiões plásticos por habitante do que os Estados Unidos. Disponível em http://www.medplan.com.br/materias/2/22195 .html. Acesso em 15.11.2011.

MACEDO, Letícia. Polícia investiga morte de atriz durante lipoaspiração em São Paulo. Disponível em http://g1.globo.com/saopaulo/noticia/2012/10/policia-investigamorte-de-atriz-durante-lipoaspiracao-emsp.html. Acesso em 03.10.2012.

MCLUHAN, Marshall. Os meios de comunicação como extensões do homem.
Trad. Decio Pignatari. São Paulo: Cultrix, 1980.

NÓBREGA, Terezinha Petrucia da.

Corporeidade e Educação Física. Do corpoobjeto ao corpo-sujeito. Natal: UFRN, 2005.

PARRY, John. Psicologia da comunicação humana. Trad. Octavio Mendes Cajado. São Paulo: Cultrix, 1980.

PATERNOSTRO, Vera Isis. O texto na TV. São Paulo: Campus, 2007.

PEÑA-CASANOVA, J. Manual de Fonoaudiologia. Porto Alegre: Artes Médicas, 1997.

POLITO, Reinaldo. Como falar corretamente e sem inibições. São Paulo: Saraiva, 2006. p. 281 -287.

QUINTEIRO, Euclosia Acuña. Manual de terapia corporal como base da estética da voz e da fala. Carapicuiba: Pró-Fono Departamento Editorial, 2000.

RECTOR, Mônica e TRINTA, Aluízio Ramos. Comunicação do corpo. São Paulo: Vozes, 1999.

SANTAELLA, Lucia. Corpo e comunicação: sintonia da cultura. São Paulo: Paulus, 2004.

SILVA, Maria Julia Paes da. Comunicação tem remédio: a comunicação nas relações interpessoais em saúde. São Paulo: Loyola, 2005.

VILLAÇA, Nízia; GÓES, Fred; KOSOVSKI, Ester. Que corpo é esse? Novas perspectivas. São Paulo: Mauad, 1999.

ZEMLIN, Willard. R. Princípios de Anatomia e Fisiologia em Fonoaudiologia. Trad. Terezinha Oppido. Porto Alegre: Artes Médicas Sul, 2000. 
WEIL, Pierre. O corpo fala: a linguagem

silenciosa da comunicação não-verbal.

Petrópolis: Vozes, 1998.

\footnotetext{
${ }^{\mathrm{i}} \mathrm{O}$ body building é um conceito peculiar e relativamente moderno: o corpo vivo como objeto público, termo que descreve a construção da massa muscular - desligada da ideia de força e de saúde pelo uso de pesos e exercícios com máquinas (GÓES, Fred. In: VILLAÇA, GÓES, KOSOVSKI, 1999, 35).

ii $\mathrm{O}$ conceito de body modification traduz a prática baseada na tecnologia da cirurgia plástica, nas técnicas do piercing e da tatuagem, além da química dos esteroides. (GÓES, Fred. In: VILLAÇA, GÓES, KOSOVSKI, 1999, 37).

${ }^{i i i}$ Arte do corpo, popularizada a partir da década de 1960, podendo ter ligações com o happening e a performance e ser apresentada ao público através de vídeos ou fotografias.

${ }^{\mathrm{N}}$ Disponível online:

http://www.claudiacotes.com.br/site/download/tese mestrado.pdf

$\checkmark$ Em sociedade, todo homem busca manter com os outros um intercâmbio de informações, ideias, sentimentos. As formas de contato, postas em prática para este objetivo social levam à instauração de relações de natureza biopsicossocial, permitindo o estabelecimento de padrões de conduta individual e coletiva. Pela observação dos modos de comportamento, socialmente aceitos e validados, chega-se a um conhecimento empírico desta comunicação de conduta, forma particular de comunicação de ordem cultural (RECTOR, TRINTA, 1993, p. 25).

${ }^{\mathrm{v}}$ Ciência que tem como objeto de estudo a comunicação humana, o seu desenvolvimento, aperfeiçoamento e os distúrbios em relação aos aspectos envolvidos na função auditiva periférica e central, além das funções vestibular e cognitiva; a linguagem oral e escrita - nos propicia informações relevantes para esse estudo Disponível online: http://www.fonoaudiologia.com/

vii Disponível online:

http://www.claudiacotes.com.br/site/download/tese_mestrado.pdf

viii O Homem Vitruviano é um desenho de 1492, do cientista, matemático, inventor, anatomista, pintor, escultor, arquiteto Leonardo da Vinci, que expõe traçado e proporções do corpo humano. É também uma referência à obra Os dez livros da Arquitetura, do arquiteto romano Marco Vitruvio Polião.

${ }^{\mathrm{ix}} \mathrm{http}$ ://www.medplan.com.br/materias/2/22195.html

http://g1.globo.com/sao-paulo/noticia/2012/10/policia-investigamorte-de-atriz-durante-lipoaspiracao-em-sp.html

${ }^{x i}$ Disponível em

www.rbceonline.org.br/revista/index.php/RBCE/article/view/139

xii $I d$.

xiiihttp://www.itaucultural.org.br/aplicexternas/enciclopedia_ic/index. cfm?fuseaction $=$ termos texto\&cd verbete $=3177$

${ }^{x i v}$ Id.
}

De certa forma, foi uma liberação prá mim perceber o quanto as minhas emoções sempre estiveram à mostra. Saber que as pessoas haviam me compreendido muito além daquilo que eu fora capaz de lhes dizer, em palavras... *Flora Davis 